eCommons@AKU

October 2010

\title{
Antibiotic susceptibility patterns of Helicobacter pylori and triple therapy in a high-prevalence area
}

Javed Yakoob

Aga Khan University

Shahab Abid

Aga Khan University, shahab.abid@aku.edu

Z.Abbas

Aga Khan University

S. N. W. Jafri

Aga Khan University

Follow this and additional works at: https://ecommons.aku.edu/pakistan_fhs_mc_med_med Part of the Digestive System Diseases Commons, and the Gastroenterology Commons

\section{Recommended Citation}

Yakoob, J., Abid, S., Abbas, Z., Jafri, S. (2010). Antibiotic susceptibility patterns of Helicobacter pylori and triple therapy in a highprevalence area. British Journal of Biomedical Science, 67(4), 197-201.

Available at: https://ecommons.aku.edu/pakistan_fhs_mc_med_med/6 


\title{
Antibiotic susceptibility patterns of Helicobacter pylori and triple therapy in a high-prevalence area
}

\author{
J. Yakoob, S. Abid, Z. Abbas \& S. N. W. Jafri
}

To cite this article: J. Yakoob, S. Abid, Z. Abbas \& S. N. W. Jafri (2010) Antibiotic susceptibility patterns of Helicobacter pylori and triple therapy in a high-prevalence area, British Journal of Biomedical Science, 67:4, 197-201, DOI: 10.1080/09674845.2010.11730319

To link to this article: https://doi.org/10.1080/09674845.2010.11730319

曲 Published online: 23 May 2016.

Submit your article to this journal $\pi$

Џll Article views: 7

Citing articles: 5 View citing articles $\square$ 


\section{Antibiotic susceptibility patterns of Helicobacter pylori and triple therapy in a high-prevalence area}

\author{
J. YAKOOB, S. ABID, Z. ABBAS and S. N. W. JAFRI \\ Department of Medicine, The Aga Khan University, Karachi, Pakistan
}

Accepted: 1 June 2010

\section{Introduction}

Helicobacter pylori is a Gram-negative spiral bacterium. Its association with gastritis, gastric and duodenal ulcers, gastric adenocarcinoma and mucosa-associated lymphoid tissue (MALT) lymphoma is well established, ${ }^{1}$ and has a worldwide distribution. Seroprevalence of H. pylori in Karachi, Pakistan, in healthy children aged 11-15 years is reported as $53.5 \% .^{2}$

Successful eradication of $H$. pylori infection requires the use of an antibiotic regimen to which the infecting strain is susceptible. ${ }^{3}$ The Maastricht consensus report on H. pylori advised that the first-line treatment should be a drug regimen that includes a proton pump inhibitor (PPI) and two antimicrobial agents (clarithromycin plus amoxicillin or clarithromycin plus metronidazole). ${ }^{4}$ The triple therapy usually results in an eradication rate $>80 \%$.

In recent years, the emergence of antibiotic-resistant H. pylori strains has been reported, posing a significant threat to successful treatment. ${ }^{3,5-6}$ In a previous multicentre study in patients with active duodenal ulcer, one week of triple therapy with PPI, amoxicillin and clarithromycin eradicated H. pylori infection. ${ }^{7}$ Low cure rate and a higher resistance to clarithromycin have been observed among H. pylori-positive patients with functional dyspepsia. ${ }^{8-10}$

In practice, $H$. pylori infection currently is being treated in most centres in Pakistan without knowledge concerning the incidence of resistant strains. For most bacterial infections, antibiotic susceptibility testing is routinely carried out but the specialised growth requirements of $H$. pylori preclude such tests in most diagnostic medical laboratories. There is limited local published information that includes data on the antibiotic susceptibility of this pathogen. ${ }^{11-12}$ In a study conducted in the north of Pakistan, the antimicrobial susceptibility of $H$. pylori isolates from 43 specimens determined by the Kirby Bauer technique against amoxycillin, clarithromycin and metronidazole demonstrated that $67 \%$ were resistant to metronidazole, while all the isolates were sensitive to amoxycillin, clarithromycin and tetracycline. ${ }^{12}$

The aim of this study is to determine the effect of primary H. pylori resistance to antibiotics used for triple therapy that included clarithromycin (CLR, $500 \mathrm{mg}$ ), amoxicillin (AMX, $1 \mathrm{~g})$ and omeprazole $(40 \mathrm{mg})$ twice a day for two weeks, and

Correspondence to: Dr Javed Yakoob

Department of Medicine, The Aga Khan University Hospital, Stadium Road, Karachi-74800, Pakistan

Emailyakoobjaved@hotmail.com

\section{ABSTRACT}

This study aims to determine primary Helicobacter pylori resistance and its effect on eradication of the organism. Ninety-two patients with dyspeptic symptoms were enrolled. H. pylori was cultured and antibiotic sensitivity was determined by the Epsilometer test (Etest) for clarithromycin (CLR), amoxicillin (AMX) and metronidazole (MTR). $23 \mathrm{~S}$ ribosomal RNA (rRNA) point mutations associated with clarithromycin resistance were also detected. Patients were treated with omeprazole (40 mg daily), CLR (500 mg) and AMX (1g twice a day) for 14 days. $\mathrm{A}{ }^{14} \mathrm{C}$-urea breath test $\left({ }^{14} \mathrm{C}\right.$-UBT) was repeated four weeks after completion of treatment to confirm eradication. Triple therapy failure was seen in 30(33\%) patients. The resistance rates were: CLR 33\% (30/92), MTR $48 \%$ (44/92) and AMX 2\% (2/92). Clarithromycin resistance (CLR-R) was present in the 16-39 age group in $21(47 \%)$ $(P=0.007)$ compared to nine $(19 \%)$ in the $40-79$ age group. CLR resistance was seen in $30 \mathrm{H}$. pylori isolates, $20(67 \%)$ from patients with non-ulcer dyspepsia (NUD), six (20\%) with gastric ulcer (GU) and four (13\%) with duodenal ulcer (DU). Triple therapy failure was associated with CLR-R in $28(93 \%)(P<0.001)$. CLR-R mutations were present in $30(33 \%)$ and were associated with treatment failure in 27 (90\%; $P<0.001)$. They were present in $20(44 \%)$ isolates obtained from patients in the $16-39$ age group $(P=0.018)$. Treatment failure was associated with A2142G mutation in 20 (67\%; $P<0.001)$, A2143G mutation in $12(40 \%$; $P<0.001)$ and $\mathrm{A} 2142 \mathrm{C}$ mutation in five $(17 \% ; P=0.003)$. In conclusion, triple therapy failure was associated with CLR-R. Metronidazole resistance exceeded that of CLR, hence it cannot be substituted for CLR in a triple therapy.

KEY WORDS: Clarithromycin.

Drug resistance, microbial.

Helicobacter pylori.

Metronidazole.

its effect on eradication of $H$. pylori in patients with nonulcer dyspepsia (NUD) and peptic ulcer disease (PUD). Eradication was documented by performing a ${ }^{14} \mathrm{C}$-urea breath test $\left({ }^{14} \mathrm{C}\right.$-UBT) four weeks after completion of treatment. Also determined is the prevalence of $23 \mathrm{~S}$ ribosomal RNA (rRNA) point mutations associated with clarithromycin resistance in $H$. pylori isolates.

\section{Materials and methods}

H. pylori strains

Over the 24 months of the study period (February 2007 to January 2009), a total of $92 \mathrm{H}$. pylori isolates were obtained from patients referred for endoscopy at the Aga Khan 
University (Table 1). Inclusion criteria comprised a history of upper abdominal pain requiring histological definition, symptoms suggestive of peptic ulcer, and where gastric biopsy was indicated by endoscopy finding. Ethical approval for the collection of extra biopsies was granted by the Aga Khan University Ethics Review Committee.

Upper endoscopy was performed and gastric biopsy samples were obtained in triplicate from within $5 \mathrm{~cm}$ of the pylorus along the greater curvature for culture and histopathology. H. pylori infection was defined by i) positive culture, ii) positive histopathology, and iii) positive rapid urease test.

\section{Culture and identification of $\mathrm{H}$. pylori}

The specimens were transported immediately in sterile normal saline to isolate $H$. pylori. Thus, within three hours of collection each specimen was homogenised in sterile Eppendorf tubes with an electric homogeniser. The resulting suspension was inoculated onto Columbia blood agar (Oxoid) medium and Dents supplement (containing vancomycin, trimethoprim and polymyxin) and incubated at $37^{\circ} \mathrm{C}$ under microaerophilic conditions for 4-6 days. Plates were then examined for bacterial growth and typical colonies were selected for identification. The identity of H. pylori was confirmed by Gram stain and by the production of urease and catalase. One half of the homogenate was used for culture and the other half was kept at $-80^{\circ} \mathrm{C}$. H. pylori isolates were defined as Gramnegative spiral-shaped bacilli that were catalase-positive and rapidly (less than $1 \mathrm{~h}$ ) urease-positive. H. pylori NCTC

Table 1. Characteristics of the study patients from which $\mathrm{H}$. pylori isolates were obtained.

\begin{tabular}{l|lc}
\hline \multirow{2}{*}{ Age } & Mean \pm SD & $43 \pm 15$ \\
& Range & $16-79$ \\
& Age group 16-39 years & $43(47)$ \\
& Age group 40-79 years & $49(53)$ \\
\hline Gender & Male & $62(67)$ \\
& Female & $30(33)$ \\
\hline Symptoms & Abdominal pain & $46(83)$ \\
& Heartburn & $5(5)$ \\
& Diarrhoea & $8(9)$ \\
& Haematemesis & $3(3)$ \\
\hline Diagnosis & Non-ulcer dyspepsia & $57(62)$ \\
& Gastric ulcer & $15(16)$ \\
& Duodenal ulcer & $20(22)$ \\
\hline${ }^{14}$ C Urea breath test & Positive & $30(33)$ \\
& Negative & $62(67)$ \\
\hline Clarithromycin & Sensitive & $62(67)$ \\
& Resistant & $30(33)$ \\
\hline Metronidazole & Sensitive & $48(52)$ \\
& Resistant & $44(48)$ \\
\hline Amoxicillin & Sensitive & $90(98)$ \\
\hline & Resistant & $2(2)$ \\
\hline
\end{tabular}

Data shown as patient numbers (\%).

Results presented as mean \pm standard deviation for quantitative variables.
11637 (type strain) was used as a positive control for the culture conditions and identification tests.

\section{Antibiotic susceptibility testing}

Antibiotic susceptibility was determined on Mueller Hinton agar (Oxoid, UK) containing 10\% defibrinated sheep blood and a cell suspension calibrated at three McFarland units by Epsilometer test (Etest) using metronidazole, clarithromycin and amoxycillin Etest strips (AB Biodisk, Solna, Sweden). Plates were read after three days at $37^{\circ} \mathrm{C}$. The tests were carried out according to the manufacturer's instructions. For Etests, minimum inhibitory concentration (MIC) breakpoints of $\geq 2 \mathrm{mg} / \mathrm{L}$ and $\geq 8 \mathrm{mg} / \mathrm{L}$ were used for metronidazole and clarithromycin, respectively. Intermediate susceptibility (MIC $2-8 \mathrm{mg} / \mathrm{L}$ ) was also recorded for metronidazole. High-level resistance to both antibiotics was defined as MIC $>256 \mathrm{mg} / \mathrm{L}$. The breakpoint MIC used for amoxicillin was $\geq 2 \mathrm{mg} / \mathrm{L} .^{13} \mathrm{H}$. pylori NCTC 11637 was used as a sensitive control.

\section{Rapid urease test}

Urea agar base enriched with $40 \%$ urea solution (eUAB, Oxoid) was used as a rapid urease test. ${ }^{14}$ It shows $97 \%$ sensitivity, $86 \%$ specificity, $84 \%$ positive predictive value (PPV), 97\% negative predictive value (NPV) and 91\% accuracy to detect urease activity of $H$. pylori in gastric biopsy.

\section{Histological analysis}

Formalin-fixed, paraffin wax-embedded gastric biopsy specimens were routinely processed. Gastritis activity was graded on a four-point scale of none (grade 0), mild (grade 1), moderate (grade 2), and severe (grade 3) according to the guidelines of the Sydney system. ${ }^{15}$ Presence of $H$. pylori was assessed on modified Giemsa-stained sections.

\section{Urea breath test}

A ${ }^{14} \mathrm{C}$-UBT procedure was undertaken using methodology described previously. ${ }^{16}$ In a previous study, the accuracy of ${ }^{14} \mathrm{C}$-UBT was compared to histopathology and rapid urease test. Accuracy was 93\% compared to histopathology, while PPV and NPV were $97 \%$ and $84 \%$, respectively. ${ }^{17}$ Comparison of ${ }^{14} \mathrm{C}$-UBT with rapid urease test gives an accuracy of $96 \%$, with PPV and NPV of 95\% and 97\%, respectively. These results were highly reproducible $(P<0.001) .{ }^{17}$

\section{Extraction of genomic DNA}

Bacterial cells grown on chocolate agar were washed $(x 2)$ with phosphate-buffered saline (PBS) then centrifuged at $3000 \mathrm{xg}$ for $20 \mathrm{~min}$. H. pylori DNA was extracted by a phenol/chloroform method as described previously. ${ }^{18}$ Briefly, the bacterial pellet was resuspended in Tris- $\mathrm{HCl}$ buffer containing ethylenediaminetetraacetate (TE, $\mathrm{pH}$ 8.0) and lysozyme $(30 \mathrm{mg} / \mathrm{mL})$ and then incubated at $37^{\circ} \mathrm{C}$ for $30 \mathrm{~min}$. The suspension was treated with sodium dodecyl sulphate (SDS, $10 \%)$, proteinase $\mathrm{K}(2.5 \mathrm{mg} / \mathrm{mL})$ and RNase A $(40 \mathrm{mg} / \mathrm{mL})$. DNA was extracted with phenol/chloroform/isoamyl alcohol, precipitated by sodium acetate and ice-cold absolute alcohol, and the washed with ice-cold alcohol (70\%). The DNA pellet was resuspended in TE buffer. The DNA content and purity were determined by measuring absorbance at 
Table 2. Distribution of antibiotic sensitivities.

\begin{tabular}{|c|c|c|c|c|c|c|c|c|c|c|}
\hline & & \multicolumn{3}{|c|}{ Clarithromycin } & \multicolumn{3}{|c|}{ Metronidazole } & \multicolumn{3}{|c|}{ Amoxicillin } \\
\hline & & $\begin{array}{c}\text { Sensitive } \\
(n=62)\end{array}$ & $\begin{array}{c}\text { Resistant } \\
(n=30)\end{array}$ & $P$ value & $\begin{array}{l}\text { Sensitive } \\
(n=48)\end{array}$ & $\begin{array}{c}\text { Resistant } \\
(n=44)\end{array}$ & $P$ value & $\begin{array}{c}\text { Sensitive } \\
(n=90)\end{array}$ & $\begin{array}{l}\text { Resistant } \\
\quad(n=2)\end{array}$ & $P$ value \\
\hline \multirow[t]{2}{*}{ Age groups } & $16-39$ years & $24(53)$ & $21(47)$ & 0.005 & $22(49)$ & $23(51)$ & 0.537 & $44(98)$ & $1(2)$ & 0.975 \\
\hline & 40-79 years & $38(81)$ & 9 (19) & & $26(55)$ & $21(45)$ & & 46(98) & $1(2)$ & \\
\hline Diagnosis & Mean age & & & & & & & & & \\
\hline Non-ulcer dyspepsia & $40 \pm 15$ & $37(65)$ & $20(35)$ & & $30(53)$ & $27(47)$ & & $56(98)$ & $1(2)$ & \\
\hline Gastric ulcer & $46 \pm 15$ & $9(60)$ & $6(40)$ & 0.725 & $4(27)$ & $11(73)$ & 0.088 & 14(93) & $1(7)$ & 0.376 \\
\hline Duodenal ulcer & $45 \pm 13$ & $16(80)$ & $4(20)$ & 0.269 & $14(70)$ & $6(30)$ & 0.177 & $20(100)$ & $0(0)$ & \\
\hline \multirow[t]{2}{*}{${ }^{14} \mathrm{C}$ Urea breath test } & Positive & $2(7)$ & $28(93)$ & $<0.001$ & $16(53)$ & $14(47)$ & 0.877 & $29(97)$ & 1(3) & 0.548 \\
\hline & Negative & $60(97)$ & $2(3)$ & & $32(52)$ & $30(48)$ & & $61(98)$ & $1(2)$ & \\
\hline
\end{tabular}

$260 \mathrm{~nm}$ and $280 \mathrm{~nm}$ using a spectrophotometer (Beckman DU-600, USA).

\section{Polymerase chain reaction}

A 267 bp fragment was amplified by PCR using extracted DNA as the template, as previously described, using primers 5'-AGGTTAAGAGGATGCGTCAGTC-3' (HPY-S) and 5'-CGCATGATATTCCCATTAGCAGT-3' (HPY-A), corresponding to nucleotides 1931-1952 and 2197-2175, respectively, of the 23S rRNA gene of $H$. pylori (GenBank Accession No U27270). ${ }^{19}$ Amplification was carried out in a total volume of $50 \mathrm{~mL}$ containing $1 \times \mathrm{PCR}$ reaction buffer, $1.5 \mathrm{mmol} / \mathrm{L} \mathrm{MgCl}_{2}, 200 \mu \mathrm{mol} / \mathrm{L}$ each of four dNTPs, $0.2 \mathrm{mmol} / \mathrm{L}$ primers (synthesised by MWG), 2 unit of Thermus aquaticus (Taq) DNA polymerase (Promega) and $2 \mathrm{~mL}$ extracted DNA. The reaction was carried out in a Perkin Elmer 9700 thermal cycler. Amplification cycle comprised an initial denaturation of target DNA at $94^{\circ} \mathrm{C}$ for $5 \mathrm{~min}$ and then denaturation at $94^{\circ} \mathrm{C}$ for $1 \mathrm{~min}$, primer annealing at $55^{\circ} \mathrm{C}$ for $1 \mathrm{~min}$ and extension at $72^{\circ} \mathrm{C}$ for $1 \mathrm{~min}$. The final cycle included an extension step for $7 \mathrm{~min}$ at $72^{\circ} \mathrm{C}$ to ensure full extension of the product. The samples were amplified through 35 consecutive cycles. Negative reagent control reactions were performed with each batch of amplifications, consisting of tubes containing DNA isolated from $H$. pylori-negative patients. After amplification, PCR products were precipitated and the pellets washed in $70 \%$ ethanol and resuspended in $25 \mu \mathrm{L}$ sterile distilled water. The PCR products $(3 \mu \mathrm{L})$ were subjected to electrophoresis in 2\% agarose gel to ensure homogeneity and yield. Amplification resulted in a homogeneous DNA fragment of the expected size.

The amplified products obtained were subjected to restriction endonuclease digestion for $2 \mathrm{~h}$ at $37^{\circ} \mathrm{C}$ in a $20 \mu \mathrm{L}$ volume..$^{20}$ The digested samples were analysed by agarose gel $(3 \%[\mathrm{w} / \mathrm{v}])$ electrophoresis. Restriction enzymes BbsI (5 units), BsaI (5 units) and BceAI (0.5 units) (New England Biolabs) were used on the basis of sequence data available for this amplified product. Restriction fragment length polymorphism (RFLP) allowed the identification of the A2142G and A2143G mutations using the BbsI and $B s a I$ restriction enzymes, respectively, as previously described. ${ }^{21,22}$ The enzyme BceAI recognised, on the $267 \mathrm{bp}$ amplified product, two sites 5 '-ACGGC(N)122N-'3 and 5'-N2(N)12GCCGT-3', yielding two restriction fragments from the wild-type and three from the A2142G and A2143G mutants (195, 48 and 24), while BceAI yielded four from the $\mathrm{A} 2142 \mathrm{C}$ mutation, recognising an additional site, 5'-ACGGC(N)122N-3'. The amplified PCR products were resolved in 3\% agarose gel containing Tris/acetate/EDTA, stained with ethidium bromide and visualised under an ultraviolet light source.

\section{Statistical assessment}

The Statistical Package for Social Science (SPSS, Release 16, standard version) was used for data analysis. Results were presented as mean \pm standard deviation (SD) for quantitative variables and number $(\%)$ for qualitative variables. Differences in proportion were assessed using Pearson's $\chi^{2}$, Fisher exact or likelihood ratio tests where appropriate. $P<0.05$ was considered statistically significant.

\section{Results}

Triple therapy failure was seen in $30(33 \%)$ patients. The primary antibiotic resistance rates are shown in Table 1. Dual resistance to CLR and AMX was present in two (2\%) cases, to CLR and MTR in $13(14 \%)$, and one patient showed resistance to all three antibiotics.

Sensitivity and resistance data by age group are shown in Table 2. Dual resistance to CLR and MTR was seen in $11(85 \%)$ patients in the 16-39 ago group compared to two $(15 \%)$ in the $40-79$ age group $(P=0.007)$. The resistance rate

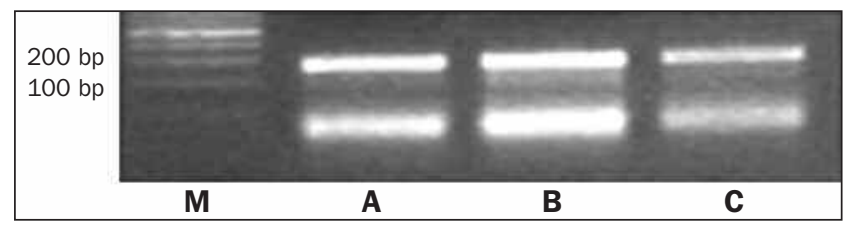

Fig. 1. Polymerase chain reaction-restriction fragment length polymorphism (PCR-RFLP) pattern of 23S rRNA genes from patients with clarithromycin resistance. Lane $\mathrm{M}$, DNA size marker; PCR-RFLP pattern obtained with Bbs1 (lane A), BceA1 (lane B) and Bsa1 (lane C). 
to CLR and MTR did not show a gender distribution. Correlation of diagnosis with antibiotic susceptibilities is shown in Table 2, as is association with triple therapy failure, which was associated with resistance to CLR in $28(93 \%)$ cases $(P<0.001)$. A breakdown of treatment failure is shown in Table 3. Details of the correlation between treatment failure and mutation is shown in Figure 1 and Table 3.

The CLR resistance mutations were present in 30 (33\%) H. pylori isolates. These mutations were associated with treatment failure in $27(90 \%)$ cases $(P<0.001)$. These mutations were present in $20(44 \%) \mathrm{H}$. pylori isolates from patients in the 16-39 age group and $10(21 \%)$ in the $40-79$ age group $(P=0.018)$, and were present in $19(33 \%)$ patients with NUD, four $(20 \%)$ with DU $(P=0.262)$ and seven $(47 \%)$ with GU $(P=0.339)$.

\section{Discussion}

This study demonstrated a triple therapy failure rate of $30 \%$. It was found more frequently in those under 40 years of age who had NUD. However, the difference was not significant in those with NUD compared to those with PU. Resistance to AMX was seen in a small number of patients, while MTR is not used locally as a part of triple therapy for H. pylori infection, although it is commonly prescribed for infectious diarrhoea of both bacterial and parasitic origin.

The implication of this study is that there is a high degree of MTR resistance in $H$. pylori isolates so it cannot be used instead of CLR in triple therapy regimens. Metronidazole resistance may be associated with previous use of the drug. ${ }^{23}$ In contrast to the findings reported here, Mirza et al., from the north of Pakistan, reported $100 \%$ sensitivity to CLR and AMX, which shows that resistance to CLR has evolved in the south of the country. ${ }^{12}$

Clarithromycin resistance may be associated with preexistent resistance to other macrolides (e.g., erythromycin) or infection with $H$. pylori strains with DNA mutations associated with CLR resistance. These mutations are known to be associated with different MIC values in vitro. A very low eradication rate (48\%) occurred in the A2143G mutated strains, while the rate was higher than $90 \%$ in the absence of this mutation. ${ }^{23}$ In addition to use in the treatment of H. pylori infection, CLR is commonly prescribed for the treatment of acute exacerbation of chronic bronchitis in adult patients in the community. In Pakistan, selfprescription is also common and medications are available for sale without prescriptions. ${ }^{24,25}$

Erythromycin is among the most frequently used agents. ${ }^{24}$ High levels of resistance have been found to ampicillin, cotrimoxazole and erythromycin..$^{25}$ Poultry use has increased with rising inflation, and poultry production largely depends on the use of antibiotics, and erythromycin is commonly used. ${ }^{26}$ Owing to indiscriminate use and unawareness of adequate withdrawal periods, antibiotic residues are known to be present in the meat. This is unfit for human consumption and known to alter intestinal bacterial flora and encourage the development of resistant bacteria. ${ }^{27}$ Akhtar et al. cultured 58 isolates of Salmonella enteritidis from stool samples of patients with diarrhoea, all of which showed resistance to erythromycin. ${ }^{28}$

South Asia is a low-risk region for gastric cancer but has a high prevalence of $H$. pylori. ${ }^{29}$ Locally, the incidence of gastric
Table 3. Correlation of treatment with diagnosis.

\begin{tabular}{|c|c|c|c|c|}
\hline & & \multicolumn{2}{|c|}{ Treatment } & \multirow[t]{2}{*}{$P$ value ${ }^{*}$} \\
\hline & & $\begin{array}{l}\text { Failure } \\
(n=30)\end{array}$ & $\begin{array}{l}\text { Success } \\
(n=62)\end{array}$ & \\
\hline \multirow[t]{2}{*}{ Age groups } & 16-39 years & $19(42)$ & $26(58)$ & 0.054 \\
\hline & $40-79$ years & $11(23)$ & $36(77)$ & \\
\hline \multicolumn{5}{|l|}{ Diagnosis } \\
\hline Non-ulcer dyspepsia & $n=57$ & $19(33)$ & $38(67)$ & \\
\hline Gastric ulcer & $n=15$ & $6(40)$ & $9(60)$ & 0.629 \\
\hline Duodenal ulcer & $n=20$ & $5(25)$ & $15(75)$ & 0.489 \\
\hline \multirow[t]{2}{*}{ A2142G } & Positive & 20(91) & 2(9) & $<0.001$ \\
\hline & Negative & $10(14)$ & $60(86)$ & \\
\hline \multirow[t]{2}{*}{ A2143G } & Positive & $12(92)$ & $1(8)$ & $<0.001$ \\
\hline & Negative & $18(23)$ & $61(77)$ & \\
\hline \multirow[t]{2}{*}{ A2142C } & Positive & $5(100)$ & $0(0)$ & 0.003 \\
\hline & Negative & $25(29)$ & $62(71)$ & \\
\hline
\end{tabular}

Data shown as patient numbers (\%).

$P<0.05$ was considered statistically significant.

carcinoma has been increasing, markedly in males over 40 years of age..$^{29}$ A recent study concluded that primary care physicians lacked knowledge regarding the management of H. pylori infection. ${ }^{30}$ Only $57 \%$ would confirm $H$. pylori eradication after treatment in selected patients, and $47 \%$ physicians preferred serological testing for follow-up.

In conclusion, this study has shown that MTR resistance exceeds CLR resistance in $H$. pylori isolates from patients with upper gastrointestinal symptoms. In view of this finding, MTR cannot be used in place of CLR in patients who demonstrate CLR-based triple therapy failure.

This study was supported by a research grant from URC of the Aga Khan University to JY and SA.

\section{References}

1 Ernst PB, Gold BD. The disease spectrum of Helicobacter pylori: the immunopathogenesis of gastroduodenal ulcer and gastric cancer. Annu Rev Microbiol 2000; 54: 615-40.

2 Jafri W, Yakoob J, Abid S, Siddiqui S, Awan S, Nizami S. Helicobacter pylori infection in children: population-based age-specific prevalence and risk factors in a developing country. Acta Paediatr 2010; 99 (2): 279-82.

3 Alarcon T, Domingo D, Lopez-Brea M. Antibiotic resistance problems with Helicobacter pylori. Int J Antimicrob Agents 1999; 12: 19-26.

4 Malfertheiner P, Megraud F, O'Morain C et al. Current concepts in the management of Helicobacter pylori infection: the Maastricht III Consensus Report. Gut 2007; 56: 772-81.

5 Glupczynski Y, Megraud F, Lopez-Brea M, Andersen LP. European multicentre survey of in vitro antimicrobial resistance in Helicobacter pylori. Eur J Clin Microbiol Infect Dis 2001; 20: 820-5.

6 Qasim A, Morain CA. Review article: treatment of Helicobacter pylori infection and factors influencing eradication. Aliment Pharmacol Ther 2002; 16 (Suppl 1): 24-30. 
7 Wong BC, Chang FY, Abid S et al. Triple therapy with clarithromycin, omeprazole and amoxicillin for eradication of Helicobacter pylori in duodenal ulcer patients in Asia and Africa. Aliment Pharmacol Ther 2000; 14: 1529-35.

8 Graham DY. Antibiotic resistance in Helicobacter pylori: implications for therapy. Gastroenterology 1998; 115: 1272-7.

9 Houben MH, van de Beek D, Hensen EF, Craen AJ, Rauws EA, Tytgat GN. A systematic review of Helicobacter pylori eradication therapy: the impact of antimicrobial resistance on eradication rates. Aliment Pharmacol Ther 1999; 13: 1047-55.

10 Broutet N, Tchamgoue S, Pereira E, Lamouliatte H, Salamon R, Mégraud F. Risk factors for failure of $H$. pylori therapy results of an individual data analysis of 2751 patients. Aliment Pharmacol Ther 2003; 17: 99-109.

11 Mirza SH, Hannan A, Rizvi F. Helicobacter pylori isolation from gastric biopsy specimens. Ann Trop Med Parasitol 1993; 87: 483-6.

12 Mirza IA, Mirza SJ, Ali AM. Antimicrobial susceptibility pattern of H. pylori in isolates from Northern Pakistan. Int J Path 2007; 5: $18-20$.

13 King A. Recommendations for susceptibility tests on fastidious organisms and those requiring special handling. J Antimicrob Chemother 2001; 48 (Suppl 1): 77-80.

14 Yakoob J, Abid S, Jafri W, Abbas Z, Islam M, Ahmad Z. Comparison of biopsy-based methods for the detection of Helicobacter pylori infection. Br J Biomed Sci 2006; 63: 159-62.

15 Price AB. The Sydney System: histological division. J Gastroenterol Hepatol 1991; 6: 209-22.

16 Hegedus O, Ryden J, Rehnberg AS, Nilsson S, Hellstrom PM. Validated accuracy of a novel urea breath test for rapid Helicobacter pylori detection and in-office analysis. Eur J Gastroenterol Hepatol 2002; 14: 513-20.

17 Rasool S, Abid S, Jafri W. Validity and cost comparison of 14carbon urea breath test for diagnosis of $H$. pylori in dyspeptic patients. World J Gastroenterol 2007; 13: 925-9.

18 Yakoob J, Hu GL, Fan XG et al. Diversity of Helicobacter pylori among Chinese persons with $H$. pylori infection. APMIS 2000; 108: 482-6.

19 Ménard A, Santos A, Mégraud F, Oleostro M. PCR-restriction fragment length polymorphism can also detect point mutation
A2142C in the $23 \mathrm{~S}$ rRNA gene associated with Helicobacter pylori resistance to clarithromycin. Antimicrob Agents Chemother 2002; 46: $1156-7$.

20 Sambrook J, Fritisch EF, Maniatis T. Molecular cloning: a laboratory manual 2nd edn. Cold Spring Harbor: Cold Spring Harbor Laboratory Press, 1989: 1847-55.

21 Occhialini AM, Urdaci F, Doucet-Populaire C, Bebear CM, Lamouliatte H, Megraud F. Macrolide resistance in Helicobacter pylori: rapid detection of point mutations and assays of macrolide binding to ribosomes. Antimicrob Agents Chemother 1997; 41: 2724-8.

22 Versalovic, JD, Shortridge D, Kibler $\mathrm{K}$ et al. Mutations in $23 \mathrm{~S}$ rRNA are associated with clarithromycin resistance in Helicobacter pylori. Antimicrob Agents Chemother 1996; 40: 477-80.

23 Xia HX, Daw MA, Beattie S, Keane CT, O'Morain CA. Prevalence of metronidazole-resistant Helicobacter pylori in dyspeptic patients. Ir J Med Sci 1993; 162: 91-4.

24 De Francesco V, Margiotta M, Zullo A et al. Clarithromycinresistant genotypes and eradication of Helicobacter pylori. Ann Intern Med 2006; 144: 94-100.

25 Siddiqi S, Hamid S, Rafique G et al. Prescription practices of public and private health care providers in Attock district of Pakistan. Int J Health Plann Manage 2002; 17: 23-40.

26 Sturm AW, van der Pol R, Smits AJ et al. Over-the-counter availability of antimicrobial agents, self-medication and patterns of resistance in Karachi, Pakistan. J Antimicrob Chemother 1997; 39: 543-7.

27 Athar M, Ahmad MT. Vet's Guide - A Manual of Veterinary Products 2nd edn. Faisalabad, Pakistan: Worldwide Publishers, 1996.

28 Mumtaz A, Awan JA, Athar M. Rational use of drugs in broiler meat production. Int J Agri Biol 2000; 2: 269-72.

29 Akhtar F, Hussain I, Khan1 A, Rahman SU. Prevalence and antibiogram studies of Salmonella enteritidis isolated from human and poultry sources. Pakistan Vet J 2010; 30: 25-8.

30 Bhurgri Y, Pervez S, Kayani N et al. Rising incidence of gastric malignancies in Karachi, 1995-2002. Asian Pac J Cancer Prev 2009; 10: $41-4$.

31 Ahmed S, Salih M, Jafri W, Ali Shah H, Hamid S. Helicobacter pylori infection: approach of primary care physicians in a developing country. BMC Gastroenterol 2009; 9: 23. 